\title{
ESTRUTURA DE CONCORRÊNCIA E ESTRATÉGIA DE PREÇO NO MERCADO BRASILEIRO DE AVIAÇÃO CIVIL
}

\author{
Competition structure and price strategy in the brazilian aviation \\ market
}

Thiago Cavalcante de Souza

E-mail: thiagocs@ufu.br

Doutor em Economia no Programa de Pós-graduação em Economia da Universidade Federal de

Uberlândia; Mestre em Economia Regional e Políticas Públicas pela Universidade Estadual de

Santa Cruz; Bolsista da Coordenação de Aperfeiçoamento de Pessoal de Nível Superior (Capes);

Economista.

Endereço para contato: Avenida João Neves de Ávila, 2121, Campus Santa Mônica - BilJ, 38408-144, Uberlândia, Minas Gerais, Brasil. https://orcid.org/0000-0002-4629-5137

Sarah Farias de Andrade

E-mail: lorelai97@yahoo.com.br

Mestra em Economia Regional e Políticas Públicas pela Universidade Estadual de Santa Cruz; Doutoranda em Economia no Programa de Pós-graduação em Economia da Universidade Federal da Bahia; Bolsista da Coordenação de Aperfeiçoamento de Pessoal de Nível Superior (Capes);

Economista. https://orcid.org/0000-0002-8807-6135

Aniram Lins Cavalcante E-mail: aniramlyns@yahoo.com.br

Doutora em Desenvolvimento pela Universidade Estadual de Santa Cruz; Mestra em Desenvolvimento Regional e Meio Ambiente pela Universidade Estadual de Santa Cruz; Bolsista de

Pós-doutorado em Economia Regional e Políticas Públicas pela Coordenação de Aperfeiçoamento de Pessoal de Nível Superior (Capes) e pela Universidade Estadual de Santa Cruz.

https://orcid.org/0000-0003-2006-2041

Artigo recebido em 22 de janeiro de 2018. Aceito em 8 de outubro de 2019. 


\section{Resumo}

Este trabalho analisa o padrão de competição, os preços e a estrutura de mercado do mercado brasileiro de aviação civil, tomando como referência a oferta e demanda de assentos no tráfego doméstico. São utilizados como procedimentos metodológicos os indicadores de concentração CRN (4...8) e o Índice Herfindahl-Hirschman (IHH). Adotou-se o modelo X-12 Autoregressive Integrated Moving Averag (ARIMA) para realizar a análise sazonal dos preços tarifários. Os resultados demonstram que grande parcela do mercado brasileiro de aviação civil é dominada por um pequeno grupo de companhias aéreas, confirmando a hipotese central de oligopolização do mercado traçada neste trabalho. Diante da estrutura oligopolista, observou-se que as estratégias de competição das firmas estão associadas à ampliação da capacidade de oferta e captação de passageiros, muitas vezes evidenciada pela concentração da malha aérea e aumentos de slots aeroportuários centrais. A análise da sazonalidade apontou maior efeito na série de tarifas referente aos meses de julho e março. A análise de intervenção realizada apontou o mês de julho de 2010 como ponto significativo, período em que entra em vigor a Resolução da Agência Nacional de Aviação Civil (ANAC) de controle de qualidade, sugerindo que a regulação governamental exerce influência sobre as estratégias adaptativas das firmas desse segmento.

Palavras-chave: Aeroportos. Aviação. Concentração. Preços. Transporte.

\section{Abstract}

This paper analyzes the competition pattern, prices and market structure of the Brazilian civil aviation market, taking as reference a supply and demand of seats on the domestic road. The concentration indicators CRN (4...8) and the Herfindahl-Hirschman Index (HHI) are used as methodological procedures. The Averag Movente Integrated Autoregressive Model was adopted to perform a seasonal analysis of the tariff prices. The results show that a small group of airlines, signaling an oligopoly market. In view of the oligopolistic structure, it was observed that the firms' competition strategies are associated with the expansion of the supply and passenger capacity, often evidenced by the concentration of the air network and increases in the central airport lanes. The analysis of seasonality showed a greater effect on the series of tariffs for the months of July and March. An analysis of the intervention carried out pointed out the month of July 2010 as a significant point, when ANAC's quality control Resolution comes into effect, suggesting that government regulation exerts influence on the adaptive strategies of firms.

Keywords: Airports. Aviation. Concentration. Prices. Transportation.

\section{INTRODUÇÃO}

O mercado brasileiro de aviação civil comercial passou por inúmeras transformações desde a década de 1990, quando ocorreram a desregulamentação tarifária do setor e a ampliação da malha aérea no âmbito da abertura comercial no País. De um mercado incipiente, com poucos aeroportos e reduzido número de companhias aéreas, o Brasil passou a configurar um setor com empresas aéreas mais robustas, que se afastando do modelo de aviação doméstico-regional, adotaram o padrão doméstico-internacional, interligando os complexos aeroportuários interioranos aos sítios aeroportuários dos principais destinos 
internacionais, por meio do modelo de distribuição operacional de voos hub,' instalados nas principais capitais do País.

Com a adoção do sistema de escalas e conexões (hub-and-spoke), o mercado brasileiro de aviação ampliou a oferta de voos para os trechos de longo alcance, antes inacessíveis às companhias aéreas regionais e aos aeroportos instalados no interior dos estados brasileiros. Esse sistema também contribuiu para a cooperação entre companhias aéreas nacionais e internacionais, em que as empresas atuantes em um determinado sítio aeroportuário transferem o passageiro para outra companhia aérea, responsável por finalizar o trecho até o destino final do cliente, não atendido pela companhia aérea responsável pela partida inicial, mantendo, entretanto, o mesmo sistema de tarifação. Paralelamente, as diversas alterações no marco regulatório da aviação civil brasileira, advindas das políticas de liberalização dos mercados ocorridas no fim da década de 1990, contribuíram para alterações expressivas no cenário competitivo, com a proliferação de acordos internacionais de liberalização comercial e integração.

Conforme sustentam Pasin e Lacerda (2003), o processo de integração vertical e horizontal do capital alocado no setor aéreo brasileiro provocou diversos desdobramentos sobre a estrutura de concorrência na aviação doméstica comercial, como: falências, fusões e incorporações de companhias aéreas; reorganização e estrangulamento da oferta de slots aeroportuários, congestionamento do tráfego aéreo e de terminais de passageiros; e flutuação do preço das tarifas dos bilhetes aéreos, favorecendo a prática discriminatória de preços.

É, contudo, a partir dos anos 2000 que a aviação brasileira apresenta saltos expressivos. Conforme dados publicados no Anuário Estatístico do Transporte Aéreo, organizado pela Agência Nacional da Aviação Civil (ANAC, 2013), 94\% das decolagens registradas nos aeroportos brasileiros corresponderam ao tráfego aéreo entre aeroportos nacionais, sinalizando expansão das rotas e da infraestrutura aeropb ortuária nacional. Nesse período, o mercado doméstico atingiu o maior volume de oferta registrado na última década, alcançando a marca de 989 mil voos realizados e receita corrente de US\$17,4 milhões. Sumariamente, a demanda por assentos no transporte aéreo doméstico-regional registrou o patamar de 88,7 mil passageiros transportados. No mesmo período, o crescimento médio da economia e da população brasileira foi de $3,85 \%$ e $1 \%$, respectivamente. Comparando-se a esses percentuais, o transporte aéreo doméstico cresceu, em média, mais de 3,5 vezes o PIB e mais de 14 vezes a população.

Embora se observe uma relevante expansão do setor, a oferta do transporte aéreo brasileiro apresentou níveis de crescimento espacialmente concentrado, visto a existência de

Aeroporto em que uma companhia aérea possui alta disponibilidade de horários para pouso e decolagem (slots aeroportuários, cuja comercialização é de responsabilidade da administração aeroportuária). Os hubs são utilizados como ponto de conexão para transferência de passageiros a voos que os levaram até o destino final pretendido, cujo aeroporto de origem não dispõe de opções de voo direto ou mesmo não apresenta oferta de assentos suficiente. 
142 aeroportos no Brasil, frente a uma população distribuída entre os mais de 5 mil municípios. Em face dessas questões, este artigo se propõe a elucidar a forma como o mercado brasileiro de aviação comercial se encontra estruturado economicamente. Para tanto, objetiva identificar o grau de concentração do mercado brasileiro de aviação civil, referenciando-se em variáveis de estrutura, como oferta de assentos e demanda por passageiros. Sumariamente, estima-se um modelo econométrico para descrever o comportamento do preço médio das tarifas. Por razões metodológicas e de disponibilidade de dados, a análise é realizada para o período de 2005 a 2012.

O argumento traçado é que o mercado brasileiro de aviação civil se encontra estruturado sob uma dinâmica oligopolista, de forma que a concentração espacial e econômica da oferta de assentos nos voos domésticos é adotada como uma estratégia adaptativa das firmas, com a finalidade de se sustentarem no mercado e desesenvolverem barreiras à entrada nos mercados locais, a exemplo dos aeroportos de "ponte aérea". Considera-se também que - poder de concentração fornece às companias aéreas vantagens concorrenciais, como a capacidade de influenciar o preço de mercado, buscando ajustá-lo ao patamar de lucros desejados ou impor restritições de mercado para as demais firmas. Essa hipotese é analisada sob os fundamentos da Organização Industrial, com referência no paradigma EstruturaConduta-Desempenho (ECD).

Na literatura científica, o mercado brasileiro de aviação civil comercial tem sido analisado em diferentes perspectivas. Guimarães e Salgado (2003) analisaram a estrutura do mercado de aviação comercial brasileiro sob o enfoque institucionalista, apontando o processo de abertura comercial da economia brasileira como preponderante para a sua expansão. Sob a perspectiva da regulamentação da concorrência, o estudo apontou a necessidade de equidade na distribuição de slots como fundamental para viabilizar a concorrência por meio da entrada de novas companhias aéreas no mercado doméstico. Miotto, Souza, e Diehl (2008) procuraram analisar a resposta das companhias aéreas diante de choques macroeconômicos e choques concorrenciais com a entrada de novas empresas no mercado.

Diehl, Miotto, e Souza (2010) buscaram analisar o impacto da tecnologia da frota de aeronaves na estrutura de custos e na eficiência operacional das companhias aéreas brasileiras. Turolla, Lima, e Ohira (2011), em estudo sobre políticas públicas para a melhoria da competitividade da aviação brasileira, indicaram que a deficiência tecnológica e operacional de aeroportos regionais impõe barreiras à entrada de companhia aéreas no segmento regional. Em outro estudo sobre o mercado de aviação regional, Leurquin e Avelar (2016) apontaram as políticas públicas de incentivo ao desenvolvimento da aviação regional como preponderantes para a dinâmica do mercado doméstico, especialmente para a entrada de novas companhias.

Este artigo pretende contribuir com a discussão reportada, empregando o ferramental analítico da Organização Industrial. Para tanto, o artigo está estruturado em seis seções, 
além desta introdução. A segunda seção recupera elementos centrais da teoria da firma e revista trabalhos que empregam o ECD como referencial teórico-analítico. Sequencialmente, a terceira seção descreve a estratégia empírica e metodológica adotada como procedimento de análise. O desenvolvimento e a apresentação dos resultados estão organizados na quarta e na quinta seções. Finalmente, a sexta seção esboça as considerações finais e as principais conclusões alcançadas.

\section{TEORIA DA FIRMA E ESTRUTURA DE CONCORRÊNCIA}

Os mercados produtivos estão no cerne da atividade econômica, e muitas das questões mais centrais da economia estão associadas ao seu modus operandi. Porquanto sua organização determina variáveis importantes para as decisões das firmas e dos consumidores, como preço, quantidade ofertada e demandada, custos, preferências, fatores inovadores, entre outros.

Na teoria neoclássica da firma, a combinação das decisões caracteriza-se como uma forma particular de estrutura de mercado, em que imperam relações de concorrência padronizadas e perfeitas. Nessa corrente, compreende-se a firma como um agente individual e isento de qualquer autonomia de decisão, prevalecendo no seu arcabouço teórico as premissas de equilíbrio, certeza e racionalidade, resultando em uma estrutura de concorrência estática.

Um mercado perfeitamente competitivo consiste em um grande número de firmas e consumidores, pressupondo um ambiente de irrestrita mobilidade de recursos e ausência de barreiras para operar. Nesse sentido, tanto as firmas quanto os consumidores possuem todas as informações necessárias para tomar as decisões econômicas, sem exercer influência sobre o preço, dada a homogeneidade dos produtos (Mas-Colell, Whinston, \& Green, 2002).

É importante destacar, conforme Nelson e Winter (2005), que os mercados possuem imperfeições em suas relações de concorrência, definidas muitas vezes pelo número de firmas e pelo caráter de seus produtos e serviços, o que inabilita a teoria neoclássica da firma para a análise de estratégias concorrenciais e adaptativas de firmas de grande valor de mercado.

Por essa razão, as decisões de uma firma podem resultar em reflexos sobre as demais concorrentes. Em razão disso, a tomada de decisões dos vendedores e compradores de um mercado oligopolista é determinada por diversos fatores, o que dificulta a generalização das características estruturais. Para cada hipótese a respeito de decisões específicas, obtem-se resultados diferentes. Essas limitações contribuem para a inexistência de uma teoria geral do oligopólio, resultando em modelos generalistas que utilizam o preço como variável elementar.

Diante das fragilidades em aproximar essas proposições teóricas à realidade, Labini (1984) reclassifica os modelos de oligopólios em subestruturas de concorrência, considerando, nesse sentido, a estratégia de competição via diferenciação de produtos e o poder de 
mercado revelado na concentração. Nessa perspectiva, são introduzidos os conceitos de oligopólio concentrado, diferenciado e misto. Nesse primeiro, os produtos são homogêneos e o mercado caracteriza-se pela alta concentração técnica e econômica, revelado pelo número restrito de firmas dominando uma substancial parcela do mercado (POSSAS, 2008).

De acordo com Silva (2010), nos oligopólios diferenciados o esforço competitivo das firmas está concentrado na diferenciação dos produtos. Desse modo, o volume de recursos destinado à diferenciação (propaganda, tecnologia e outros) constrói no mercado um tipo particular de barreira ao ingresso de novas firmas relacionado à diferenciação. Assim, as firmas ingressantes se deparam com a necessidade de investimento compatível com o padrão concorrencial e com a reputação das firmas já existentes. Os oligopólios mistos, por sua vez, combinam concentração econômica e diferenciação nos bens e serviços ofertados ao cliente. Diante desses aspectos, Mason (1939) procurou analisar como as políticas de preço e de produção das firmas se encontravam relacionadas ao posicionamento de mercado e às características dos oligopólios em que elas estavam inseridas. Para tanto, desenvolveu um modelo teórico-analítico em que explicita a importância da organização interna das firmas (custos e produção) e da estrutura de mercado para o desempenho econômico dessas empresas.

Inspirando-se em Mason (1939), estudos econômicos realizados entre as décadas de 1960 e 1970 buscaram encontrar relações causais entre variáveis de estrutura e indicadores de desempenho empresarial, como market share. Estimativas econométricas foram realizadas a partir de amostras de atividade empresariais, procurando identificar a influência do grau de concentração de setores industriais e o nível de lucro (BAIN, 1968). O grau de concentração também foi associado ao nível de produtividade (STIGLER, 1968) e ao grau de inovação de um conjunto de firmas (Scherer, 1970). Esses estudos representam o marco teórico constitutivo do modelo ECD como paradigma analítico (Hasenclever \& Torres, 2013).

Em síntese, o modelo ECD consiste em um instrumento teórico-metodológico de análise microeconômica que permite associar as características dos oligopólios ao grau de concentração dos mercados. Segundo Lopes (2016), o modelo busca explicar o comportamento das firmas e o funcionamento dos mercados por meio da causalidade das variáveis de estrutura (custo, por exemplo) e de conduta (como preços discriminatórios, participação econômica na oferta e/ou demanda do mercado), integrando essas variáveis ao desempenho das firmas, isto é, aos números relativos aos resultados obtidos pelas firmas, como receitas, por exemplo.

Setiawan, Emvalomatis, e Lansink (2013) empregaram o paradigma ECD para investigar a relação simultânea entre a concentração industrial, a rigidez dos preços, a eficiência técnica e a margem de custo-preço na indústria de alimentos e bebidas, na Indonésia. Os resultados indicaram a existência de uma relação concomitante entre a concentração do mercado, o preço e as variáveis relativas à eficiência técnica e margem de custo com relação ao preço. Contudo, a concentração apresentou uma relação bidirecional 
positiva com a margem de preço e custo. Essas evidências demonstram-se relevantes para a tomada de decisão de policy makers no âmbito da defesa da concorrência, indicando que a redução da concentração industrial potencializa a flexibilidade de preços e tende a aumentar a eficiência técnica no longo prazo, em decorrência de ganhos concorrenciais provenientes da redução de práticas restritivas no mercado.

Peltier, Skidmore, e Milne (2013) procuraram analisar o mercado americano de gasolina, empregando um modelo de equações simultâneas fundamentado no paradigma ECD. Os autores avaliam como a estrutura de concorrência e o desempenho das firmas reagem às regulações impostas ao segmento de combustível de baixo custo (SBC). Os resultados obtidos no trabalho sugerem que as leis do SBC reduzem os preços de varejo de combustível, restringindo a práticas concorrenciais limitantes à entrada de novas firmas. Essas evidencias indicam que a institucionalidade do mercado interfere no resultado alcançado pelas estratégias concorrenciais das firmas, implicando diretamente a estrutura de concorrência via preço.

Cavalcante de Souza e Pires (2014) buscaram relacionar a concentração e estratégias concorrenciais do mercado de exibição cinematográfica ao desempenho econômico das firmas, referenciando-se no paradigma ECD. A análise baseia-se na correlação entre variáveis de estrutura ( $C R 4, C R 8, I H H)$, conduta (estratégias de diferenciação) e desempenho (receitas) dos municípios e firmas que ofertaram serviços de exibição cinematográfica no Estado da Bahia. O período de análise considerado são os anos de 2005 a 2012. Os resultados revelam que, no período analisado, o mercado de salas de cinema apresentou crescimento relevante, porém fortemente concentrado. As estratégias de concorrência para expandir o público espectador se baseiam na diferenciação das salas de cinema e formação de práticas restritivas, apontando que o aumento da demanda é limitado pela estrutura do mercado, restringindo a democratização ao acesso aos serviços culturais de exibição cinematográfica, principalmente no interior.

Ralston, Blackhurst, Canto, e Grum (2015) investigaram o efeito da integração da cadeia de suprimentos de firmas industriais sobre a demanda e o desempenho operacional e financeiro das empresas. O trabalho procurou explicitar, por meio de análise fatorial e de um modelo probabilístico de equações estruturais, a maneira pela qual as empresas usam suas atividades de integração da cadeia de suprimentos em resposta às condições de mercado. Os autores concluíram que estratégias de integração interna e externa afetam a capacidade da empresa de responder à demanda dos consumidores, o que implica positivamente o volume de receitas e o lucro. Essas evidências empíricas reforçam a relevância do modelo ECD para análise da dinâmica concorrencial de empresas industriais quanto considerados fatores organizacionais da produção.

Lee e Yang (2016) analisaram a estrutura industrial do segmento têxtil em Taiwan, propondo-se a investigar a existência de relação entre estrutura de mercado, conduta e 
desempenho das firmas. Adotou-se como estratégia empírica estimações de efeito fixo e aleatório com dados em painel e mínimos quadrados ordinários. $O$ resultado empírico indicou a existência de causalidade positiva entre variáveis de participação de mercado, barreira de entrada e intensidade de capital, e a conduta (intensidade de P\&D) e o desempenho (receitas).

\section{ESTRATÉGIA EMPÍRICA E METODOLÓGICA}

Os dados analisados neste artigo foram obtidos na Agência Nacional de Avaliação Civil (ANAC), considerando o período de 2005 a 2012 para a oferta e demanda das etapas de voo; e o período de 2002 a 2012 para o preço médio das tarifas, sendo essa a série de dados disponíveis. Foram considerados os voos cujos trechos tenham sido estabelecidos entre aeroportos de origem e de destino nacionais (domésticos). Referenciando-se na Resolução ANAC 152 (2010), a determinação da oferta do mercado considerou o produto entre a quantidade de assentos disponíveis e a quantidade de quilômetros voados entre o aeroporto de origem e o de destino, representada matematicamente pela Equação 1:

$$
A S K=\sum_{F} Q_{S} \gamma_{m}
$$

Em que representa a oferta de assentos, dada pelo somatório da multiplicação entre a quantidade de assentos ofertada por aeronave e a quilometragem de cada trecho voado do total de voos operados) por todas as companhias aéreas.

A demanda de passageiros é dada pelo número de passageiros transportados entre o aeroporto de partida e o aeroporto de destino final do passageiro (ANAC, 2010). Desconsideram-se, porém, os indivíduos transportados gratuitamente, tais como: tripulação, funcionários das companhias aéreas e seus agentes, funcionários de órgãos reguladores e crianças de colo que não ocupam assento. Define-se, portanto, a Equação 2:

$$
R P K=\sum_{F}^{N} Q_{D} \gamma_{m}
$$

Visto que consiste na demanda de passageiros, representada pelo somatório do produto entre a quantidade demandada em cada trecho voado e a quilometragem de cada trecho voado do total de voos operados) por todas as companhias aéreas.

Para mensurar a concentração econômica do mercado analisado, adotou-se como instrumento de análise os indicadores $C R(N)$ e o Índice Herfindahl-Hirschman (IHH), fundamentando-se em Hasenclever e Torres (2013) e Hoskins, McFadyen, e Finn (2004). O 
$\mathrm{CR}(\mathrm{N})$ foi ajustado com a participação das quatro $\mathrm{CR}(4)$ e oito $\mathrm{CR}(8)$ maiores companhias aéreas que operam voos domésticos nos anos analisados, representado pela Equação 3:

$$
C_{N}=\sum_{i=n}^{N}\left[\frac{Q_{i}}{\sum_{i=1}^{\mathrm{M}} Q_{i}}\right]
$$

Em que $Q$ representa a participação percentual (ASK e RPK) da companhia aérea i, $\mathrm{N}$ corresponde ao número de firmas com maior participação percentual escolhido para simulação, e $\mathrm{M}$ o número total de companhias aéreas. Classifica-se o resultado em 4 intervalos (Tabela 1):

Tabela 1

Níveis de concentração, segundo intervalo do $C R(N)$

\begin{tabular}{lrr}
\hline \multicolumn{1}{c}{ Nível } & CR4 & \multicolumn{1}{c}{ CR8 } \\
\hline Nenhuma concentração & $<25 \%$ & $<45 \%$ \\
Baixa concentração & $25 \%-49,9 \%$ & $45 \%-69,9 \%$ \\
Concentração & $50 \%-74,9 \%$ & $70 \%-89,9 \%$ \\
Alta concentração & $>75 \%$ & $>90 \%$
\end{tabular}

Nota. Adaptada de "Barreiras à concorrência e dinâmica do mercado baiano de salas de cinema: Revisitando o paradigma estrutura-conduta-desempenho," de T. Cavalcante de Souza, e M. M. Pires, 2014. Cadernos de Ciências Sociais Aplicadas, 11(4), pp. 223-249.

$\mathrm{O} \mathrm{IHH}$ analisa a estrutura de mercado, considerando a participação percentual das $\mathrm{N}$ companhias aéreas, sendo representado pela Equação 4:

$$
I H H=\sum_{i=n}^{|N|}\left(\frac{\mathrm{X}_{\mathrm{i}}}{\mathrm{T}^{2}}\right)
$$

Em que $x_{i}$ indica o tamanho (ASK e RPK) da companhia aérea individual $i$, e $T$ o tamanho total do mercado, cuja interpretação obedece aos intervalos descritos na Tabela 2:

Tabela 2

\begin{tabular}{|c|c|}
\hline Nível & $\mathrm{IHH}$ \\
\hline Nenhuma concentração & $<1.000$ \\
\hline Concentração moderada & $1.000-1.800$ \\
\hline Alta concentração & $>1.800$ \\
\hline Monopólio & $=10.000$ \\
\hline
\end{tabular}

Níveis de concentração, segundo intervalo do IHH

Nota. Adaptada de "Barreiras à concorrência e dinâmica do mercado baiano de salas de cinema: Revisitando o paradigma estrutura-conduta-desempenho," de T. Cavalcante de Souza, e M. M. Pires, 2014. Cadernos de Ciências Sociais Aplicadas, 11(4), pp. 223-249. 
Adotou-se o modelo X-12 Autoregressive Integrated Moving Averag (Arima) para realizar a análise sazonal dos preços, e o software livre DEMETRA+. Procedeu-se ao isolamento do componente sazonal identificado na série, realizando o cálculo dos pontos mínimos, máximos e médios da sazonalidade. Para a análise de intervenção das séries de preço, adotou-se o modelo ARIMA ou ARIMA sazonal, e o programa Statistica 6.0 para retirar os efeitos dos componentes temporais, tornando a série um ruído branco ${ }^{2}$ para evitar interpretações equivocadas dos movimentos da série. Foi testada a significância da intervenção a $5 \%$, para os limites superior e inferior. A verificação dos pontos de intervenção ocorreu por análise gráfica.

Essa estratégia empírica fundamentou-se nos critérios de Morettin e Toloi (2006), inclui as seguintes etapas:

a) familiarização: construção do gráfico da série, teste para a presença de tendência e sazonalidade (função de autocorrelação);

b) ajuste dos modelos de Box e Jenkins compostos por um ciclo interativo: especificação, identificação, estimação e verificação. Foi considerado o modelo ARIMA sazonal multiplicativo (SARIMA) de ordem $(p, d, q) \times(P, D, Q)_{S^{\prime}}$ dado pela Equação 5 :

$$
\phi(B) \Phi\left(B^{S}\right)\left(1-B^{S}\right)^{D}(1-B)^{d} Z_{t}=\theta(B) \Theta\left(B^{S}\right) a_{t}
$$

Em que $\phi(B)=1-\phi_{1} B-\phi_{2} B^{2}-\cdots-\phi_{p} B^{p}$ é o operador autorregressivo de ordem $\mathrm{p}$, estacionário; $\theta(B)=1-\theta_{1} B-\theta_{2} B^{2}-\cdots-\theta_{q} B^{q}$ é o operador de médias móveis de ordem $q$, invertível; $\Phi\left(B^{S}\right)=1-\Phi_{1} B^{S}-\Phi_{2} B^{2 S}-\cdots-\Phi_{P} B^{S P}$ é o operador autorregressivo sazonal de ordem P, estacionário; $\Theta\left(B^{S}\right)=1-\Theta_{1} B^{S}-\Theta_{2} B^{2 S}-\cdots-\Theta_{Q} B^{S Q}$ é o operador de médias móveis sazonal de ordem $Q$, invertível; $(1-B)^{d}$ é o operador diferença com d indicando o número de diferenças; $(1-B)^{D}$ é o operador diferença sazonal com $\mathrm{D}$ indicando o número de diferenças sazonais; $S$ corresponde ao período sazonal, $S=4$ (trimestrais) ou $S=12$ (mensais). ${ }^{3}$

c) escolha do modelo baseado no critério de Akaike Information Creiterium (AIC);

d) utilização de variáveis binárias na análise de intervenção; se houve intervenção, assumiu-se o valor 1 ; se houve ausência de intervenção, adotou-se 0 .

\footnotetext{
Erro aleatório com média e variância constante e sem autocorrelação.

Mais detalhes podem ser encontrados em Box, Jenkins e Reinsel (1994) e Morettin e Toloi (2006).
} 
De acordo com Bueno (2012) e Morettin e Toloi (2006), as séries em que há intervenção podem ser representadas por dois tipos de variáveis binárias:

a) Função degrau (step function), em que o efeito da intervenção se mantém após o instante do tempo T até o final da série (Equação 5).

$$
X_{j, t}=S(T)_{t}=\left\{\begin{array}{l}
0, t<T \\
1, t \geq T
\end{array}\right.
$$

b) Função impulso, em que o efeito da intervenção é temporário, afetando apenas a série no instante $T$ (Equação 6).

$$
X_{j, t}=S(T)_{t}=\left\{\begin{array}{l}
0, t \neq T, \\
1, t \equiv T
\end{array}\right.
$$

\section{ESTRUTURA DE CONCORRÊNCIA E PADRÃO DE CONCENTRAÇÃO}

O mercado brasileiro de aviação civil apresenta poucos elementos concorrenciais, assemelhando-se a uma estrutura de mercado oligopolista, pois quatro companhias aéreas concentram mais que $90 \%$ do market share da oferta do transporte aéreo doméstico. Analisando-se a participação das oito maiores companhias aéreas, esse percentual atinge quase $100 \%$. Verificou-se uma tendência de centralização do mercado, e alta concentração em todos os anos, com oscilações entre 2005 e 2010 e expansão a partir de 2011 (Tabela 3). Essa oscilação no cenário competitivo se deve, em grande parte, à regulamentação do marco regulatório ${ }^{4}$ da aviação civil e à criação da ANAC em 2005, que passou a regular e fiscalizar a outorga de serviços aéreos no Brasil e compor, administrativamente, os conflitos de interesses entre prestadoras de serviços aéreos e de infraestrutura aeronáutica e aeroportuária. 
Tabela 3

Medidas de concentração, em termos de oferta de assentos, do mercado brasileiro de aviação civil (2005-2012)

\begin{tabular}{cccc}
\hline \multirow{2}{*}{ Ano } & \multicolumn{3}{c}{ Índice } \\
\cline { 2 - 4 } & $\mathrm{CR}_{4}$ & $\mathrm{CR}_{8}$ & $\mathrm{IHH}$ \\
\hline 2005 & 97,03 & 99,09 & 3428 \\
2006 & 95,08 & 98,54 & 4183 \\
2007 & 96,71 & 99,04 & 4329 \\
2008 & 97,92 & 99,62 & 3719 \\
2010 & 95,08 & 99,81 & 3419 \\
2011 & 89,43 & 99,79 & 3138 \\
2012 & 91,43 & 99,93 & 3235 \\
Média & 94,41 & 99,98 & 3428 \\
\hline
\end{tabular}

Em 2006, observou-se uma desaceleração da concentração econômica para os dois coeficientes de centralidade parciais (CR4 e CR8). Entretanto, o índice de análise sumária (IHH) apontou uma elevação da concentração em termos globais, o que indica um avanço da concentração individual de uma das firmas ou a perda de competitividade de uma das firmas líderes do mercado. Esse fenômeno é ainda melhor observado em 2007, quando o $\mathrm{IHH}$ atinge o maior nível de concentração no período analisado. Tal resultado pode ser explicado pela instabilidade que atingiu o mercado brasileiro de aviação civil, após a crise financeira da companhia aérea Varig, que deixou de operar diversos trechos aéreos em razão da diminuição em sua frota de aeronaves provocada por processos judiciais de penhora movidos por credores.

Muitos aeroportos deixaram de ser atendidos por voos regulares, exigindo uma redistribuição dos slots aeroportuários. Entretanto, poucas foram as companhias aéreas que se beneficiaram desse processo de redistribuição das concessões de slots por parte da ANAC, pois havia inúmeras exigências institucionais, a fim de se preservar a capacidade operacional das companhias aéreas. Destaca-se, também, o alto volume de investimento necessário para absorver os hubs dos sítios aeroportuários centrais, antes operados pela Varig, em decorrência da "remuneração" aos ganhos de eficiências que tais aeroportos proporcionariam às companhias aéreas que neles ingressassem, convergindo, assim, para barreiras à entrada, conforme salientou Bain (1968).

Ademais, as interrupções das atividades da Varig revelaram uma série de problemas estruturais na operacionalização do trafego aéreo do Brasil, atingindo as atividades de pousos e decolagens dos diversos complexos aeroportuários do País. Acrescentam-se, também, os dois grandes acidentes aeronáuticos protagonizados no País; o primeiro em 2006, quando a aeronave que operava o voo 1907 da companhia Gol Linhas Aéreas colidiu com um jato Legacy e caiu em um trecho de mata fechada no Norte do Estado do Mato Grosso; e o segundo, com a aeronave da TAM Linhas Aéreas, que durante o pouso ultrapassou o fim 
da pista 35L do Aeroporto Internacional de Congonhas em São Paulo, chocando-se com um depósito de cargas.

Diante dos números levantados, observa-se que a distribuição do market share individual apontou a TAM como a principal ofertante de assentos por quilômetros transportados. Infere-se, portanto, que essa firma vem se beneficiando na negociação de slots e hubs, o que lhe concede liderança de mercado e, consequentemente, melhores condições de preço médio das tarifas do setor aéreo. Dessa forma, a firma amplia sua capacidade de absorção da demanda, pois pode operar um maior número de trechos através do sistema hub-and-spoke (Tabela 5).

A oferta de assentos é influenciada pela capacidade de assentos de cada aeronave. Assim, para que uma companhia aérea possa ampliar a capacidade de oferta de assentos por voo, terá que alocar aeronaves de maior porte e capacidade de peso transportado. Essa operação, no entanto, envolve um maior custo, visto que esse tipo de aeronave requer maior volume de combustível e possui maiores apólices de seguro por voo realizado.

Em termos de demanda de passageiros, o mercado doméstico de aviação civil manteve o padrão de alta concentração, registrando média de $94,86 \%$ e 99,58\% para o CR4 e o CR8, respectivamente. Esses resultados demonstram que as oito maiores companhias aéreas que atuam no País concentraram quase $100 \%$ dos passageiros transportados no período analisado (Tabela 4). Esse cenário representa uma dimensão relevante da estrutura de concorrência, pois o controle do mercado por um pequeno número de companhias aéreas implica a conduta e o desempenho das companhias aéreas rivais. Nessa perspectiva, entendese que a magnitude da demanda que as companhias aéreas absorvem no País reflete a dinâmica do mercado, especialmente quanto às decisões de preços e à diferenciação dos serviços de bordo e atendimento.

Medidas de concentração, em termos de demanda de passageiros, do mercado brasileiro de aviação civil (2005-2012)

\begin{tabular}{cccc}
\hline \multirow{2}{*}{ Ano } & \multicolumn{4}{c}{ Índice } & $\mathrm{HHI}$ \\
\cline { 2 - 4 } 2005 & $\mathrm{CR}_{4}$ & $\mathrm{CR}_{8}$ & 3052 \\
2006 & 97,64 & 99,39 & 3562 \\
2007 & 95,93 & 98,85 & 4250 \\
2008 & 97,07 & 99,21 & 4348 \\
2009 & 98,01 & 99,65 & 3650 \\
2010 & 95,15 & 99,81 & 3405 \\
2011 & 88,96 & 99,83 & 3029 \\
2012 & 91,14 & 99,95 & 3262 \\
\hline Média & 94,97 & 99,99 & 3570 \\
\hline
\end{tabular}


Tabela 5

Oferta de assentos por quilometro transportado por companhias aéreas presentes no mercado doméstico de aviação civil (2005-2012)

\begin{tabular}{|c|c|c|c|c|c|c|c|c|}
\hline \multirow{2}{*}{ Empresa } & \multicolumn{8}{|c|}{ Ano } \\
\hline & 2005 & 2006 & 2007 & 2008 & 2009 & 2010 & 2011 & 2012 \\
\hline Abaeté & 5.403 & 8.897 & 5.888 & 2.513 & 2.878 & 336 & 165 & \\
\hline Air Minas & - & - & 30.530 & 34.408 & 39.313 & 2.601 & - & 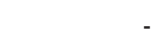 \\
\hline Ata Brasil & 21.883 & - & - & - & - & - & - & - \\
\hline Avianca (lcao:One) & - & - & - & - & 180.257 & 231.890 & 372.540 & 597.535 \\
\hline Azul-Lin Aéreas & - & - & - & 30.012 & 357.093 & 655.293 & 897.146 & 990.470 \\
\hline Bra & 2.233 .351 & 2.198 .168 & 1.836 .913 & - & - & - & - & - \\
\hline Cruiser & 19.783 & 20.857 & 8.867 & - & 490 & - & - & . \\
\hline Gol & 12.452 .698 & 18.325 .965 & 28.141 .511 & 32.460 .679 & 34.796 .329 & 3.644 .140 & 3.989 .106 & 3.609 .508 \\
\hline Mega & 5.048 & 285 & - & - & - & - & - & - \\
\hline Meta & 52.551 & 36.766 & 22.391 & 23.116 & 1.637 & 1.306 & - & - \\
\hline Nht & - & - & 26.647 & 34.086 & 3.059 & 2.577 & 3.043 & 1.837 \\
\hline Noar & - & - & - & - & - & 2.233 & - & - \\
\hline Oceanair & 224.040 & 1.013 .449 & 1.723 .847 & 1.962 .592 & - & - & - & - \\
\hline Pantanal & 177.056 & 177.819 & 168.497 & 140.498 & 11.704 & - & - & - \\
\hline Passaredo & 21.370 & 39.391 & 70.112 & 150.853 & 39.734 & 65.467 & 70.229 & 40.215 \\
\hline Puma Air & 36.699 & 33.784 & 14.359 & 5.948 & 119 & 33.499 & - & . \\
\hline Rico & 313.645 & 318.222 & 241.067 & 75.145 & 6.101 & - & - & . \\
\hline Sete Linha Aéreas & - & - & - & - & 1.801 & 4.257 & 3.607 & 4.305 \\
\hline Sol & - & - & - & - & 1.050 & - & - & - \\
\hline Taf & 3.962 & 127.086 & 265.179 & 62.054 & - & - & - & - \\
\hline Tam-Lin Aéreas & 20.938 .649 & 26.044 .401 & 30.768 .678 & 35.148 .043 & 39.011 .121 & 4.112 .779 & 4.221 .987 & 4.065 .979 \\
\hline Team & 2.549 & 7.979 & 9.439 & 9.410 & 647 & 706 & 554 & - \\
\hline Total & 292.861 & 340.915 & 375.898 & 95.117 & 5.995 & 6.258 & 6.250 & 5.895 \\
\hline Trip & 205.691 & 252.953 & 336.435 & 850.869 & 155.932 & 269.316 & 451.953 & 496.556 \\
\hline Webjet & 109.031 & 212.325 & 551.729 & 1.756 .656 & 424.179 & 489.198 & 578.558 & - \\
\hline Vrg-Lin Aer. & - & 147.902 & - & - & - & - & - & - \\
\hline Grupo Varig & 13.066 .153 & 6.300 .722 & - & - & - & - & - & - \\
\hline Total & 50.182 .423 & 55.607 .886 & 64.597 .987 & 72.841 .999 & 75.039 .440 & 9.521 .855 & 10.595 .137 & 9.812 .299 \\
\hline
\end{tabular}

Com relação ao mercado doméstico de transporte aéreo de passageiros, observase que as decisões relativas ao preço do mercado são lideradas por duas companhias aéreas que mantêm a liderança do setor: TAM e Gol. Nesse mercado, essa prática tem se demonstrado predatória, pois as companhias aéreas que não conseguem sustentar preços menores em razão dos custos operacionais tendem a ser "expulsas" do mercado. Destacase, nesse sentido, o fechamento de algumas firmas que, por meio da competição via preço, viram-se obrigadas a encerrar suas operações. Como consequência, o mercado brasileiro de aviação civil tem sido marcado pela falência de firmas (Varig e Vasp) e pela fusão e incorporação (WEBJET, OCEANAIR, TRIP). 


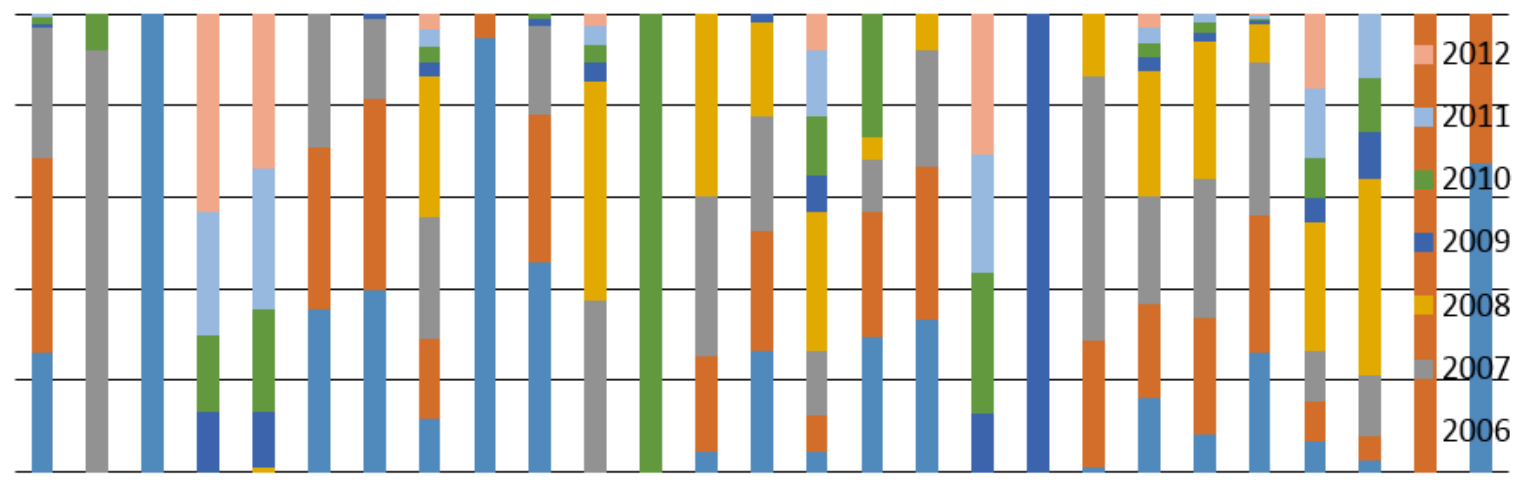

Figura 1. Participação individual das companhias aéreas na absorção de passageiros (ASK) do mercado doméstico de aviação civil (2005-2012). Adaptada de "Estátística," da Agência Nacional de Aviação Civil, 2013.

\section{I ESTRATÉGIAS DE PREÇOS NO MERCADO DE AVIAÇÃO CIVIL}

A identificação da sazonalidade determinística nas séries de preço e a demanda do setor aéreo foram significativas para a sazonalidade estável e móvel. Entretanto, a combinação dos testes de sazonalidade identificou variações temporais no preço das tarifas em determinadas épocas do ano (sazonalidade provavelmente presente), porém não constatadas para a série de demanda de passageiros (provavelmente não presentes). Todas as duas séries foram ajustadas com modelos SARIMA, sendo que a série da demanda apresentou uma decomposição multiplicativa e a série das tarifas apresentou tendência aditiva, o que indica que no caso da primeira foi necessária aplicação da diferença para torná-la estacionária (Tabela 6).

Tabela 6

Testes de sazonalidade para séries de preço (Tarifa) e quantidade de assentos-Brasil (Janeiro/2002Setembro/2012)

\begin{tabular}{ccccccc}
\hline & F Estável & $\begin{array}{c}\text { Estável Kruskal- } \\
\text {-Wallis }\end{array}$ & Móvel & $\begin{array}{c}\text { Combinado Sazonalida- } \\
\text { de Identificável }\end{array}$ & Q & Modelo \\
\hline Quant. & p-valor & p-valor & p-valor & & & \\
Preço & 0,0000 & 0,0000 & 0,0000 & P. N. P. & 0,92 & $(1,1,0)(0,1,0)$ \\
\hline
\end{tabular}

Nota. Sazonalidade estável de 0\% (0,00) a 0,1\% (0,001); Kruskal-Wallis de 0\% $(0,00)$ a 1\%(0,01); sazonalidade móvel de 0\% $(0,00)$ a $5 \%(0,05)$; S.P. (Sazonalidade Presente), N.P. (Não Presente) e P.N.P. (Provavelmente Não Presente) e Teste $\mathrm{Q}$ de $0 \%(0,00)$ a $100 \%(1,0)$.

A análise do padrão sazonal da série do preço médio das tarifas apresenta maior efeito sazonal no mês de julho, de maneira que as viagens realizadas nesse período têm custos mais elevados para os consumidores. Observou-se que no segundo semestre do ano há maior efeito sazonal. Tal comportamento pode ser explicado pelo fenômeno turístico formado por um conjunto de feriados no País e férias escolares. Nesse sentido, as companhias 
aéreas tendem a ajustar o preço médio das tarifas para compensar a ampliação da frota e inclusão de trechos exclusivos nessas datas. Com relação ao efeito sazonal das quantidades de assentos comercializados, é maior no mês de março, o que reflete menor tarifa nesse período (Figura 2), o que pode explicar o período de retorno das férias de final de ano.

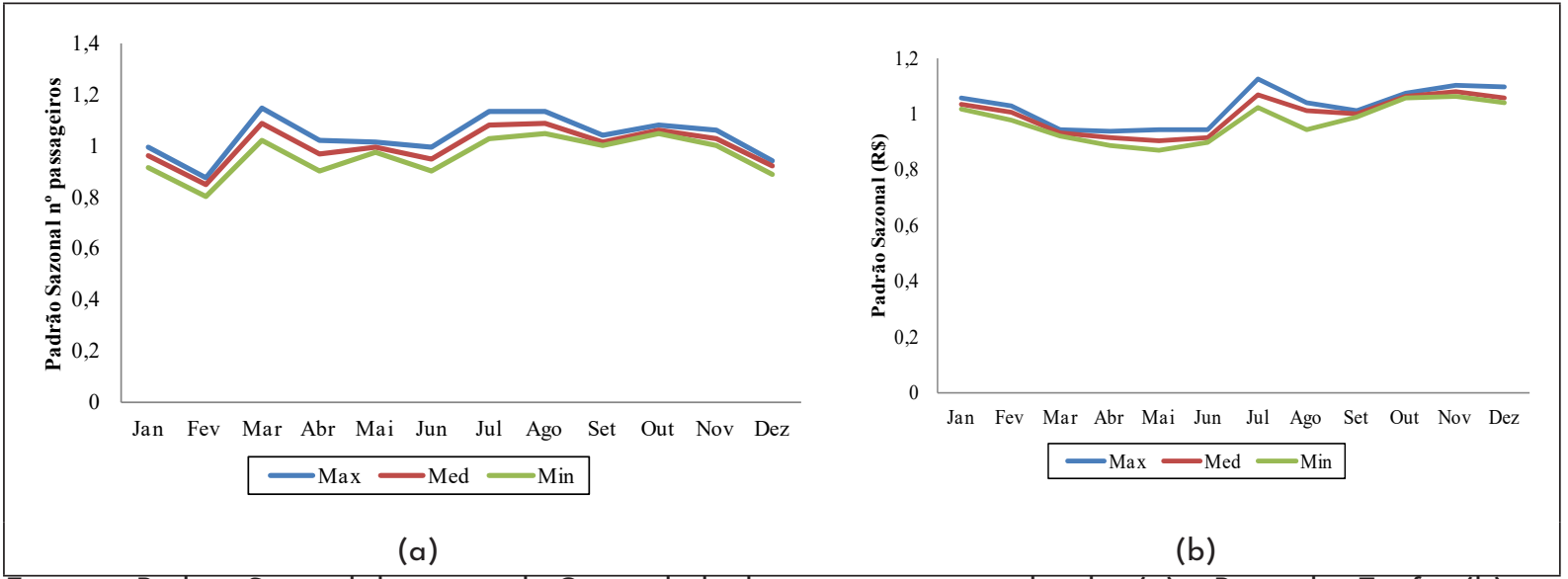

Figura 2. Padrão Sazonal das séries de Quantidade de assentos comercializados (a) e Preço das Tarifas (b)Brasil (janeiro de 2002 a setembro de 2012).

Com relação à análise de intervenção para a evolução da demanda por passagens aéreas, realizou-se a série de dados ao modelo SARIMA $(0,1,1)(1,0,0)_{12^{\prime}}$ que tornou a série um ruído branco, como pode ser observado pela função de autocorrelação dos resíduos, sendo o escolhido para análise de intervenção e previsão da série, em conformidade ao critério FAC (Figura 3).

Dessa forma, o modelo escolhido apontou um ponto de intervenção $X_{1, t^{+}}$sendo este abrupta permanente, referente ao mês de julho de 2010, quando a quantidade de assentos comercializados variou $192 \%$, tendo seus efeitos descritos na Tabela 7 :

$$
\mathrm{X}_{\mathrm{l}} \mathrm{t}=\left\{\begin{array}{l}
0, t=103 \\
1, t \neq 103
\end{array}\right.
$$

Tal modelo pode ser escrito como:

$$
Z_{t}=\frac{\omega_{1, t}}{1-B \delta_{1}} x_{1, t}+\frac{\left(1-\theta_{1} B^{1}\right)}{\left(1-\phi_{1} B^{1}\right)\left(1-\Phi_{1} B^{12}\right)(1-B)} \alpha_{t}
$$


Tabela 7

Parâmetros estimados e ponto de intervenção para série de número de assentos comercializados (Janeiro/2002-Setembro/2012)

\begin{tabular}{lccccccc}
\hline \multicolumn{1}{c}{ Parâmetros } & Estimado & $\begin{array}{c}\text { Erro pa- } \\
\text { drão }\end{array}$ & p-valor & $\begin{array}{c}\text { LI } \\
95 \%\end{array}$ & $\begin{array}{c}\text { LS } \\
95 \%\end{array}$ & Interv. & $\begin{array}{c}\text { Tipo In- } \\
\text { terv. }\end{array}$ \\
\hline$q(1)$ & 0,654549 & 0,090244 & 0,000000 & 0,475944 & 0,833154 & & \\
$\operatorname{Ps}(1)$ & 0,231756 & 0,094629 & 0,015708 & 0,044473 & 0,419039 & & \\
Omega(1) & 0,947291 & 0,107874 & 0,000000 & 0,733795 & 1,160787 & 103 & Abr/Perm \\
\hline Erro Quadrático & & & & & & 0,01952 \\
\hline
\end{tabular}

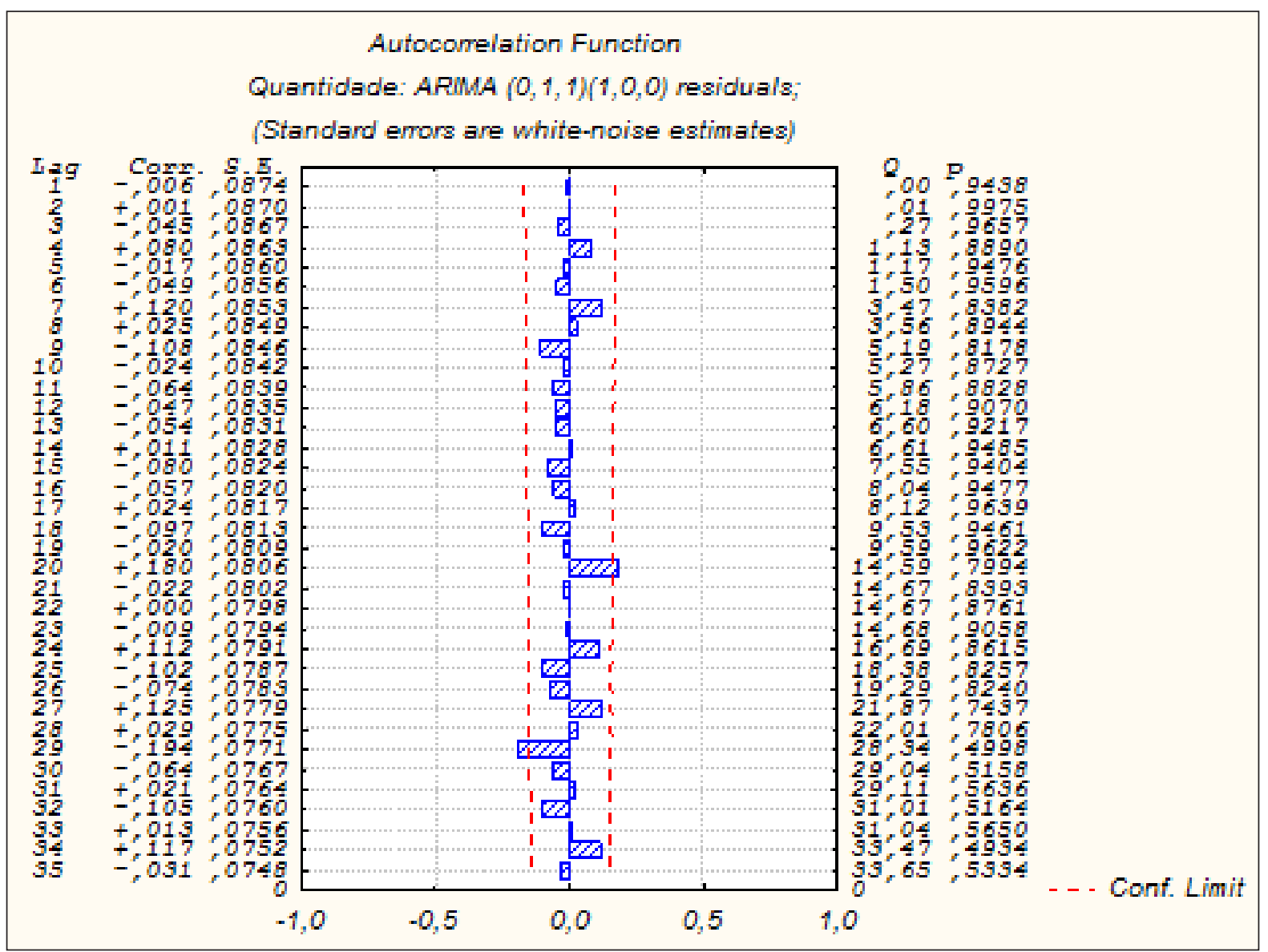

Figura 3. FAC da série de $\mathrm{n}$. de assentos comercializados no Brasil, com o modelo SARIMA $(0,1,1)(1,0,0)$ (Janeiro/2002-Setembro/2012).

A intervenção apontada no modelo pode ser visualizada por meio do gráfico da série de número de assentos comercializados no Brasil de janeiro de 2002 a setembro de 2012, em que o número de assentos sai de 1.287 .370 (junho/2010) para 3.769 .932 (julho/2010), apontando uma variação de aproximadamente $193 \%$ e que não retornou ao patamar anterior, revelando que a mudança ocorreu de forma abrupta e permanente. Nesse período, entra em vigor o Regulamento Brasileiro da Aviação Civil, por meio da Resolução ANAC 152 (2010), com o objetivo de controlar a qualidade em segurança da aviação civil contra atos de interferência ilícita. 
Nesse período, o setor aéreo brasileiro sofreu diversas interferências, como a Resolução ANAC 25 (2008), que dispõe sobre processo administrativo para apuração de infrações e aplicação de penalidades no âmbito da regulação da concorrência do setor aéreo brasileiro. Infere-se, também, que a alta na cotação do barril do petróleo (querosene de aviação QAV)-verificada entre abril e maio de 2008-afetou o principal componente dos custos das companhias aéreas, sendo repassada aos consumidores por meio de ajustes nos preços das tarifas. Nesse período, a Azul Linhas Aéreas Brasileiras iniciou suas atividades, em que suas operações privilegiaram aeroportos regionais com interligação por meio do sistema de hub-and-spoke no Aeroporto Internacional de Viracopos, em Campinas, SP.

\section{CONSIDERAÇÕES FINAIS}

Os resultados permitem inferir que a estrutura de custos das companhias aéreas determina, em grande medida, a estrutura do mercado brasileiro de aviação civil comercial. Entre a estrutura de custos operacionais, destaca-se participação do querosene de aviação, insumo altamente sensível às variações na taxa de câmbio, impondo constante volatilidade. Elementos institucionais e normativos também apresentam efeito expressivo sobre custos operacionais, em razão do elevado preço de comercialização de slots aeroportuários no Brasil e da política de adminsitração da malha aérea da ANAC, responsável por autorizar voos e rotas. Esses resultados corroboram as conclusões obtidas por Peltier et al. (2013), de que a institucionalidade do mercado importa para o desempenho obtido pelas empresas.

As medidas de concentração que foram aplicadas neste trabalho identificaram o oligopólio como estrutura de concorrência do mercado em análise, confirmando a hipótese traçada. Esse resultado é reforçado pela existência de um número limitado de companhias aéreas exercendo um alto domínio sobre os passageiros, ou seja, uma al ta parcela de mercado. Diante da estrutura oligopolista, observou-se que as estratégias de competição das firmas estão associadas à ampliação da capacidade de oferta e captação de passageiros, muitas vezes evidenciada pela concentração da malha aérea e aumentos de slots em aeroportos centrais.

As estratégias empresariais de diversificação verificadas no trabalho, como serviços de transporte de carga, aludem para a prática de economia de escopo. Porquanto o custo de transportar cargas durante os voos comerciais se demonstra inferior ao custo de se operarem voos exclusivos para o transporte de cargas de pequena dimensão, por exemplo. Esse tipo de estratégia de escopo permite às firmas reduzirem seus custos médios de operação com a diversificação dos serviços ofertados em razão da existência de reserva de capacidade, que pode ocorrer nos voos regulares em que o compartimento de carga das aeronaves é subutilizado. 
É possível que as companhias aéreas que apresentam uma maior malha aérea, quando adotarem esse tipo de estratégia de diversificação, ampliem suas vantagens com relação às firmas concorrentes. Isso porque, com a redução dos custos médios de operação, as empresas tendem a apresentar uma maior eficiência operacional. Esses ganhos podem ser potencializados quando os trajetos forem operados por aeronaves dotadas de tecnologias que resultem em menor consumo de combustível, principalmente em voos regulares entre aeroportos de "ponte aérea".

Os resultados permitem concluir a pertinência do conceito de flexibilização produtiva intrínseco ao paradigma ECD da Organização Industrial para analisar a dispersão das companhias aéreas entre os aeroportos brasileiros. Empresas que operam em aeroportos regionais e adotam o sistema multi-hubs possuem maior flexibilidade na operação, o que permite minimizar os custos operacionais e melhor distribuir os voos de conexão. Isso pode ser explicado pela possibilidade de compensação econômica (fluxo de voos) entre os múltiplos aeroportos conectivos (Congonhas, Galeão, Viracopos, Confins), pois no caso de retração de demanda em determinado trecho, a malha aérea pode ser redefinida a partir dos hubs, sendo possível manter a oferta de assento para o trecho por meio de conexão em um dos hubs da companhia.

O padrão de concentração verificado nos resultados empíricos obtidos pelo trabalho remete à existência de barreiras à entrada de novas companhias aéreas no mercado. Entre as principais razões, destacam-se os elevados custos para aquisição de aeronaves (compra ou leasing), barreiras legais para distribuição e autorização de voos e custos altos para se adquirirem slots em hubs aeroportuários. Essas práticas de restrição ao mercado concendem às empresas "líderes" uma espécie de poder de mercado virtual, que também se encontra relacionado com a capacidade de essas empresas controlarem o preço de venda das tarifas aéreas domésticas. Por isso, empresas mais eficientes, que operaram seus voos com custos de operacionais mais baixos, apresentam uma maior facilidade para competir via preço e, assim, ampliar o market share.

O padrão de concentração identificado, associado com as estratégias de diferenciação do serviço de transporte aéreo doméstico praticado no Brasil (menor tempo de conexão, programas de milhagem, refeições a bordo, maior flexibilidade para despacho de bagagens, entre outras) permitem inferir que as oito maiores companhias aéreas se defrontam com uma demanda residual negativamente inclinada, havendo espaço para fixação heterogênea de preços por tarifa aérea. Tal evidência se assemelha às conclusões obtidas por Cavalcante de Souza e Pires (2014) e Lee e Yang (2016), quando analisaram padrões de concentração e preços em outros segmentos de mercado.

A análise da sazonalidade de preço das tarifas áreas corrobora essa inferência. Porquanto se verificou maior efeito sazonal para a série de tarifas aéreas para os meses de julho e março (férias escolares e carnaval, por exemplo). Esses resultados indicam que 
um crescimento da demanda apresenta efeito positivo sobre o preço das tarifas aéreas. Elementos conjunturais da macroeconomia também se demonstram relevantes na definição da estratégia de preço.

Diante dessas conclusões, recomenda-se que a política de defesa da concorrência praticada pela ANAC seja direcionada às variáveis da estrutura e conduta das companhias aéreas, em consonancia às conclusões obtidas por Setiawan et al. (2013). Como alternativa, sugere-se um conjunto de ações reguladoras de custos, preços e padrões de qualidade, principalmente entre os aeroportos "ponte aérea". Do ponto de vista da política pública, aponta-se a adoção de subsídios à aviação regional como mecanismo relevante para impulsionar a competitividade nesse mercado e, assim, reduzir a concentração espacial. Reduzir as assimetrias de informação concernentes ao sistema de tarifação dos bilhetes aéreos pode beneficiar os consumidores, dado que a variação de preços ocorre em razão de variáveis como trecho, data da viagem, aeroporto de partida ou destino. Conhecer essas informações pode auxiliar o passageiro a escolher ou realizar combinações que resultem em preços mais baratos.

Algumas lacunas ainda persistem e sinalizam uma agenda de trabalhos futuros em que seja possível verificar o impacto exercido pela aviação regional na dinâmica concorrencial e nas flutuações do preço das tarifas no âmbito nacional. Também é importante incorporar a esse debate evidências empíricas que capturem os efeitos das estratégias de integração empresarial verificadas no segmento internacional no exercício do poder de mercado na fatia doméstica.

\section{REFERÊNCIAS}

Agência Nacional de Aviação Civil. (2013). Estatísticas. Recuperado de http://www2.anac. gov.br/estatistica/demandaeoferta/

Bain, J. S. (1968). Industrial organization. Nova lork: John Wiley.

Box, G. E. P., Jenkins, G. M., \& Reinsel, G. C. (1994). Time Series Analysis; Forecasting and Control. ( $2^{\circ}$ ed.). Englewood Cliff, New Jersey: Prentice Hall.

Bueno, R. L. S. (2012). Econometria de séries temporais. (2a ed.). São Paulo: Cengage Learning.

Cavalcante de Souza, T., \& Pires, M. M. (2014). Barreiras à concorrência e dinâmica do mercado baiano de salas de cinema: Revisitando o paradigma estrutura-conduta-desempenho. Cadernos de Ciências Sociais Aplicadas, 11(4), 223-249. 
Diehl, C., Miotto, G. R., \& Souza, M. A. (2010, Abril/Junho). Análise da tecnologia das aeronaves como determinante de custos no setor de aviação comercial brasileiro. Revista Brasileira de Gestão de Negócios, 12.

Guimarães, E. A., \& Salgado, L. H. (2003). A regulação do mercado de aviação civil no Brasil. Brasília, DF: IPEA.

Hasenclever, L., \& Torres, R. (2013). O modelo Estrutura, conduta e desempenho e seus desdobramentos. In D. Kupfer, \& L. Hasenclever (Orgs.), Economia industrial: Fundamentos teóricos e práticas no Brasil. ( $2^{a}$ ed.). Rio de Janeiro: Elsevier.

Hoskins, C., \& Mcfadyen, S., \& Finn, A. (2004). Media economics: Applying economics to new and traditional media. Thousand Oaks, US: Sage Publications.

Labini, P. C. (1984). Oligopólio e Progresso Técnico. São Paulo: Abril.

Lee, Y. C., \& Yang, Y. H. (2016, June). Analysis of industrial structure, firm conduct and performance-A case study of the textile industry. AUTEX Research Journal, 16(2), 35-42.

Lei 11.182, 2005.

Leurquin, P., \& Avelar, M. M. (2016). Os desafios jurídicos e econômicos da aviação regional no Brasil. Revista Brasileira de Políticas Públicas, 6(2), 192-212.

Lopes, H. C. (2016, Maio/Agosto). O modelo estrutura-conduta-desempenho e a teoria evolucionária neo-schumpeteriana: Uma proposta de integração teórica. Revista de Economia Contemporânea. Rio de Janeiro, 20(2), 336-358.

Mas-Colell, A., Whinston, M. D., \& Green, J. R. (2002). Microeconomic Theory. Oxford: Oxford University Press.

Mason, E. S. (1939). Price and production policies of large scale enterprise. American Economic Review, 29(1), 61-74.

Miotto, G. R., Souza, A. A. de, \& Diehl, C. A. (2008). Reflexos das mudanças na concorrência do setor de aviação comercial brasileiro: um estudo no ámbito da desrregulamentação governamental e da entrada da companhia Gol. ABCustos, 2, 94-116.

Morettin, P. A., \& Toloi, C. M. C. (2006). Análise de séries temporais. (2ª ed.). São Paulo: Edgard Blucher. 
Nelson, Richard, \& Winter, Sidney. (2005). Uma teoria evolucionária da mudança econômica. (1 $1^{a}$ ed.). Campinas: Unicamp.

Pasin, J. A. B., \& Lacerda, S. M. (2003). A reestruturação do setor aéreo e as alternativas de política para a aviação comercial no Brasil. Revista do BNDES, 19, 217-240.

Peltier, J. W., Skidmore, M., \& Milne, G. R. (2013). Assessing the Impact of Gasoline Sales-Below-Cost Laws on Retail Price and Marker Structure: Implications for Consumer Welfare. Journal of public policy e marketing, 32(2), 239-254.

Possas, M. L. (2008). Economia evolucionária neo-schumpeteriana: Elementos para uma integração micromacrodinâmica. Estudos Avançados, 22(63), 281-305.

Ralston, P. P., Blackhurst, J., Canto, D. E., \& Crum, M. R. (2015, April). A Structure-Conduct-Performance Perspective of How Strategic Supply Chain Integration Affects Firm Performance. Journal of Purchasing and Supply Chain Management, 51(2), 47-54.

Resolução ANAC 25, 2008.

Resolução ANAC 152, 2010.

Scherer, F. M. (1970). Industrial market: Structure and economic perfornance. Chicago: Rond Mcnally.

Setiawan, M., \& Emvalomatis, G., \& Lansink, A. O. (2013, December). Structure, conduct, and performance: Evidence from the Indonesian food and beverages industry. Empirical Economics, 45(3), 1149-1165.

Silva, A. L. G. (2010). Concorrência sob condições oligopolísticas: Contribuição das análises centradas no grau de atomização/concentração dos mercados. Campinas: Editora Unicamp.

Stigler, G. (1968). The Organization of Industry. Chicago: The University of Chicago Press.

Turolla, F. A., Lima, M. F. F., \& Ohira, T. H. (2011). Políticas públicas para a melhoria da competitividade da aviação regional brasileira. Revista de Literatura dos Transportes, 5(4), 188-231. 


\section{Como citar este artigo:}

\section{ABNT}

CAVALCANTE DE SOUZA, Thiago; ANDRADE, Sarah Farias de; CAVALCANTE, Aniram Lins. Estrutura de concorrência e estratégia de preço no mercado brasileiro de aviação civil. RACE, Revista de Administração, Contabilidade e Economia, Joaçaba: Editora Unoesc, v. 18, n. 3, p. 565-588, set./dez. 2019. Disponível em: http://editora.unoesc.edu.br/index. php/race. Acesso em: dia/mês/ano.

\section{APA}

Cavalcante de Souza, T., Andrade, S. F. de, \& Cavalcante, A. L. (2019). Estrutura de concorrência e estratégia de preço no mercado brasileiro de aviação civil. RACE, Revista de Administração, Contabilidade e Economia, 18(3), 565-588. Recuperado de http://editora. unoesc.edu.br/index.php/race 